\title{
Testing on the Transient Heat Loss Coefficient of All-Glass Evacuated Tube Collectors in Severe Cold Areas
}

\author{
Huifang Liu, Yiqiang Jiang, and Yang Yao
}

\begin{abstract}
The insulation features and the heat dissipation was important factors that influence the utilization of all-glass evacuated tube collector, especially in severe cold areas. The heat loss coefficient of evacuated tube collector was usually tested in given conditions, which was inapplicable for actual conditions. In this paper, further study was conducted base on the previous research of anti-freezing strategies of solar collecting loop in sever cold areas. The heat transfer of evacuated tube collector in winter night was established based on the heat balance equation. The heat loss coefficient of solar collector, as well as the possible fluid temperature in it, was tested and analyzed in detail. It indicated that the initial fluid temperature in solar collector was usually higher than $20^{\circ} \mathrm{C}$ in most of the days, and it would be still above $5^{\circ} \mathrm{C}$ throughout the whole night. The transient heat loss coefficient was mostly around at $0.4 \mathrm{~W} / \mathrm{m}^{2} \cdot \mathrm{K}$ to $0.6 \mathrm{~W} / \mathrm{m}^{2} \cdot \mathrm{K}$. The values of heat loss coefficient was steady in each night with slight reduction, which can be taken as a reference to estimate the possible fluid temperature in the solar collector and the heat dissipation in similar weather conditions. Results demonstrated that the solar collector has better insulation property, which was advantageous for the anti-freezing of collectors and outdoor pipes in severe cold areas.
\end{abstract}

Index Terms-Anti-freezing, evacuated tube collector, heat loss coefficient, heat transfer.

\section{INTRODUCTION}

The thermal performance of solar collector is a dominant element in the application of collectors. Therefore, there are many studies about the thermal property of solar collector in the daytime with solar irradiation. The heat loss coefficient is one of the indexes to estimate the quality of the vacuum and the thermal performance of the evacuated tube solar collectors. In the national standards, the mean heat loss coefficient $\left(U_{L}\right)$ was commonly used to evaluate the thermal performance of solar collectors. The testing condition of heat loss coefficient given in the standard specifications was be called as "standard testing condition" for short in this article. It refers to the thermal losses from the absorber outside surface to the surroundings in per temperature difference when there is no solar radiation, the water filled in the tubes was $80^{\circ} \mathrm{C}$ and the ambient temperature was about $20^{\circ} \mathrm{C}$. As the heat transfer of evacuated tube collector was a complicated process including conduction, convective and radiation, many

Manuscript received June 24, 2015; revised September 23, 2015. This work was supported by the National Key Technology R\&D Program in the 12th Five Year Plan of China (No. 2013BAJ12B03)

Huifang Liu, Yiqiang Jiang, and Yang Yao are with the School of Municipal and Environmental Engineering, Harbin Institute of Technology, Harbin, 150090, China (e-mail: lyliuhf@163.com, jyq7245@sina.com, yangyao1963@163.com). studies about the mean heat loss coefficient $\left(U_{L}\right)$ was conducted in standard testing condition as mentioned above. Usually it was a constant value and can't be used to calculate the thermal heat dissipation and heat collecting efficiency in real conditions. However, the heat losses of solar collector in real conditions was a function of parameters (including the ambient conditions, the fluid temperature in it, and the structural and material characteristics of evacuated tubes), which reflects the thermal insulation properties and solar collecting capacity, as well as the influence from ambient environment.

Li [1] established the heat transfer model of all-glass vacuum tube collector used in forced-circulation solar water heating system. The relationship between the collector mean temperature, the outlet temperature and natural convection flow rate have been obtained. From which the collector outlet temperature can be calculated. Bader [2] investigated the overall heat loss coefficient of vacuum tube solar collector experimentally and theoretically with regard to the pressure of the remaining gas inside the evacuated glass envelope in the standard testing condition. The temperature depended heat loss coefficient of most of the tested tubes fall into the range of $2-4 \mathrm{~W} / \mathrm{m}^{2} \cdot \mathrm{K}$. The measurement uncertainty in the mean heat loss coefficient were analysed and evaluated by Tang [3]. The study was statistically obtained by 22 repeated measurements related to the measuring devices errors and test procedure based on GB/T 17049. It implies that further revision was need on the measurement uncertainty of the mean heat loss coefficient. Moreover, Olofsson [4], [5] proposed a method for estimating the variation of the overall heat loss coefficient of some inhabited single-family buildings, which was conducted based on a neural network model. Xu [6] et al., established a dynamic test method for thermal performance of all-glass evacuated solar air collectors based on the energy balance analysis, which was also compared with steady-state conditions. The results indicated that the new methods can characterize thermal efficiency of solar collectors under more extensive conditions, reducing considerable operating time spent in waiting for the right test conditions.

However, most of the researches focused on the heat loss coefficient was conducted in steady-state conditions in the daytime as mentioned above, or the environmental condition was simplified. There was few study on heat losses that was presented in real conditions, even less in winter night time. In severe cold areas, the water capacitance in evacuated tube collectors was large, which was useful for freezing protection. As mentioned in paper [7], all-glass evacuated tube collectors as the solar collecting device, it not only can prevent the freezing of solar collector itself, but also the water in it can be 
used as the heat source of anti-freezing protection of outdoor pipes in solar collecting loop. The study in this article was its further investigation and discussion. In the paper, the heat transfer of solar collector was analyzed theoretically and experimentally in winter night, the fluid temperature in solar collector was tested and the heat losses was also analyzed. The study has important significance in the design of solar heating systems in severely cold areas, especially for the freezing protection, which can improve the economic feasibility of solar collecting system.

\section{THEORETICAL MODEL}

\section{A. Physical Model and Heat Transfer Model}

The solar collector's schematic diagram of the structure is shown in Fig. 1. All-glass vacuum tube collector consists of vacuum tubes and manifold header which interconnects the tubes and circulates heat transfer fluid. The evacuated tube consists of three parts: two glass tubes sealed at one end concentrically and there is an annular vacuum layer between the tubes. A selective coating was painting on the outside wall surface of the inner glass tube.

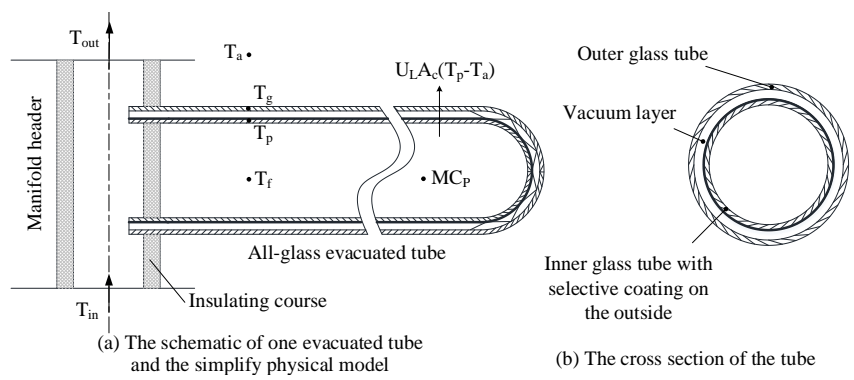

Fig. 1. The physical model of all-glass evacuated tube collector.

In winter night, as there was no solar radiation, solar collector was a pure radiator and transmit heat to the surroundings. The heat transfer of the water in the evacuated tube was natural convection circulation. The heat losses of solar collector consists the heat losses of manifold header and that of evacuated tubes. The heat losses of manifold header was mainly depended on its insulation characteristics, and it was usually regarded as a fixed value. There was a vacuum layer between the outer glass tube and inner glass tube for evacuated tube, which can reduce the convective and conductive heat losses of it. The water in the tube was cooling gradually and transmit heat to the surroundings. It first reduces along the inner surface of the inner glass tube, and it also transmit thermal heat to the selective coating layer by conduction. Then, radiation was occurred in the vacuum space from the outer surface of the selective coating layer to the outer glass tube. Finally, the heat transmitted from the outer glass tube to environment by convection and radiation. At the same time, the conduction by the bracket and the close up of the evacuated, as well as the outer glass tube were also existed. There was also heat transfer between the manifold header and tubes. The mixture water from the pre-section of manifold enters into the bottom of this tube and replaces the heated water. However, the heat transfer by conduction in the outer and inner glass tube and that by convection during the vacuum layer, as well as the heat transfer between the manifold header and tubes, can be ignored, as the amount of heat transfer was much less than the others. Hence, the overall heat transfer process can be simplified, as shown in Fig. 2. The nomenclature and symbols given in Fig. 2 was the same as that in Fig. 1(a).

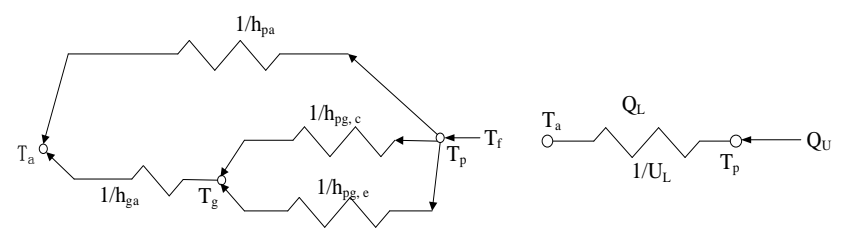

(a) Thermal network

(b) The equivalent Thermal network

Fig. 2. The thermal network diagram of the simplified heat transfer process.

In the night, there was no solar radiation, and thus the heat gains was zero. The heat transfer of evacuated tube collector can be described mathematically as

$$
Q_{u}=Q_{L}=A_{c} U_{L}\left(T_{p}-T_{a}\right)
$$

where $Q_{U}$ is the thermal capacitance of the fluid in the collector. $Q_{L}$ is the total heat dissipating of the solar collector. The heat transfer should be referenced to the outer surface area of absorber tube, $A_{c .} U_{L}$ is the total heat loss coefficient of solar collector, which can be defined as

$$
U_{L}=U_{e}+U_{b}
$$

where $U_{b}$ is the heat loss coefficient of manifold header, which depends on the surface areas, insulation thickness and the insulation conductivity of the manifold header. $U_{e}$ is the heat loss coefficient of the evacuated tube. The heat loss coefficient from the absorber tube to the ambient $U_{e}$ can be expressed as

$$
U_{e}=\frac{1}{\frac{1}{h_{g a}}+\frac{1}{h_{p g, c}+h_{p g, e}}}
$$

where $h_{g a}$ is the heat transfer coefficient from the outer glass tube to the surroundings. $h_{p g, c}$ is the heat transfer coefficient due to the conduction by the bracket and the close up of the evacuated tube. $h_{p g, e}$ represents radiation heat transfer coefficient between the absorber tube and outer glass tube, which can be written as

$$
h_{p g, e}=\sigma \varepsilon_{p}\left(T_{P}^{2}+T_{g}^{2}\right)\left(T_{p}+T_{g}\right)
$$

where $\varepsilon_{p}$ represents the emissivity of the selective absorbing coating, and $\sigma$ is Stefane Boltzmann constant. The $h_{p g, e}$ changes with temperature of the absorber tube, $T_{p}$, and the outer glass tube, $T_{g}$.

Similarly, the heat transfer coefficient of $h_{g a}$ includes the convection and radiation, and the convection should be calculated according to correlation empirical formula of $\mathrm{Nu}$ [2]. And $h_{g a, e}$ is depends on $T_{g}$ and $T_{a}$, as well as $T_{s k y}$.

The heat dissipating of evacuated tube was connected with the vacuum degree of the vacuum layer, the coating materials, 
and the structural features of the tube, etc. In addition, the liquid materials and features, the location of solar collector, and the ambient air temperature, wind speed, and sky temperature are all have relations with the heat dissipating of collectors. Generally, the heat loss coefficient and the heat transfer coefficient cannot be predicted effectively because they relate to environment and quality of production, and the parameters, such as $T_{p}, T_{g}$, and $T_{s k y}$ were not easy to be tested. In some reference, the values were given as a constant value [8], [9]. In consequence, it was a simplified and feasible way to calculate the real heat loss coefficient of solar collector according to heat balance equations, which was described in the following.

\section{B. Heat Balance Equation of Collector}

The collector consists of $n$ tubes and a manifold header, usually faces the south with a certain title angle. The detailed analysis of heat transfer in vacuum collector is a complicated problem. As there is no solar radiation in the night, the all stored heat energy in collector is only lost to the surroundings. If only circulated solar collector system in a period of time $d \tau$ in the night, the heat loss coefficient calculated equation can be described as

$$
\Delta \Phi=-M C_{p, i} \frac{d T_{f}}{d \tau}=U_{L} A_{a}\left(T_{f, i}-T_{a, i}\right)
$$

where the environment temperature is $T_{a, i}$ at any instant time $i$, and the fluid temperature is $T_{f, i}$ with specific heat of $C_{p, i}$. Moreover, the water mass capacity is $M$ and the dissipation area is $A_{a}$. According to Eq. (5), $U_{L}$ is the total heat loss coefficient of solar collector. In a time interval $\Delta \tau, U_{i}$ can be expressed as

$$
U_{L}=\frac{M C_{p, i}\left(T_{f, i}-T_{f, i-1}\right)}{A_{a}\left(T_{f, i}-T_{a, i}\right) \cdot \Delta \tau}
$$

where $T_{f, i-1}$ corresponds to the time $i-1$ and Eq. (6) can be solved if $T_{f, i}$ is known. $T_{f, i}$ can be got by the test of $T_{\text {in }}$ and $T_{\text {out }}$ in steady thermal state if the fluid is assumed to own uniform temperature in the collector. In actual project, $T_{f, i}$ is supposed to equal to the average value of $T_{i n}$ and $T_{\text {out }}$, that is, $T_{f, i}=\left(T_{\mathrm{in}, i}+\right.$ $\left.T_{\text {out }, i}\right) / 2$.

\section{EXPERIMENTAL SETUP}

In order to verify the insulation specification of solar collector itself, and anti-freezing feasibility of the outdoor pipes using the supernumerary thermal heat in collector, two similar solar heating systems were built. The experimental system consisted of a solar collecting loop (anti-freezing loop), a heat exchanging loop and a terminal heating loop, as well as data acquisition and controlling subsystems. The experiments were conducted in Harbin, China, where the solar heating season lasted from October 17 to April 10. In this system, ethylene glycol solution was used as the antifreeze fluid to avoid freezing and burst. The monthly mean air temperature of a typical meteorological year (TMY) during the heating season is listed in Table I. More detail information about the experimentation was introduced in [7].

TABLE I: THE ARRANGEMENT OF CHANNELS

\begin{tabular}{llllllll}
\hline \hline Month & 10 & 11 & 12 & 1 & 2 & 3 & 4 \\
\hline Mean air temperature & 4.2 & -6.5 & -17.7 & -18.4 & -13.9 & -2.4 & 6.7 \\
\hline \hline
\end{tabular}

The daily lowest ambient air temperature $\left(T_{a}\right)$ in November, December and January was given in Fig. 3. The experimentation was lasted from November, 2013 to March, 2014, and the daily testing period was last from 18:00 PM to 8:00 AM in the next day. During the test, there are 37 groups of data in 22 nights.

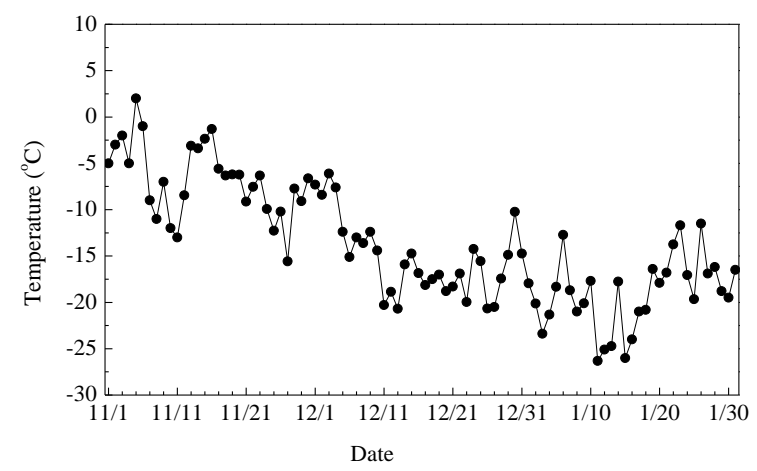

Fig. 3. The daily lowest ambient air temperature during the experiment.

\section{RESUlTS AND DisCUSSION}

In winter nights, the solar water heating system was in quiescent condition. Solar collecting loop which was composed of solar collector, water pump, outdoor pipes and heat exchanger, would dissipate heat to the surroundings gradually. Therefore, the fluid temperature in solar collector was decreased as well. The variation of the fluid temperature in solar collector is shown in Fig. 4.

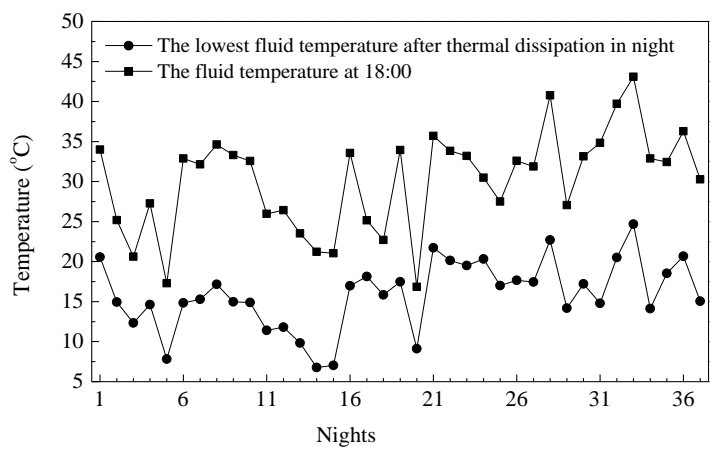

Fig. 4. The possible lowest fluid temperature and the initial temperature at 18:00 in solar collector.

As the solar radiation was changing everyday, the solar collecting capacity, and the fluid temperature, as well as the operation time of the system were all diverse. Similarly, the initial fluid temperature at 18:00 was varied. Despite all this, the initial temperature was still higher than $20^{\circ} \mathrm{C}$ in most of the days. Higher initial fluid temperature demonstrates that it was beneficial for the freezing protection in winter nights, which likewise indicates that the thermal heat in solar collector cannot be transferred to useful energy. After thermal dissipation in night, the lowest value of the fluid temperature was ranging from $5^{\circ} \mathrm{C}$ to $20^{\circ} \mathrm{C}$, which was varying with the 
initial fluid temperature and the outdoor conditions. In Harbin, China, the time of sunrise was abut 7:00 AM or even earlier. For this reason the lowest value of the fluid temperature almost occurred at the same time or slightly later. The difference of the two lines given described in Fig. 4 was the temperature drop of the fluid in solar collector in the night. Owing to the difference of heat dissipation and heat losses in different nights, the temperature drop of the fluid was diverse. The variation range of the temperature drop was also between $5^{\circ} \mathrm{C}$ to $20^{\circ} \mathrm{C}$, which was larger when the initial fluid temperature was higher.

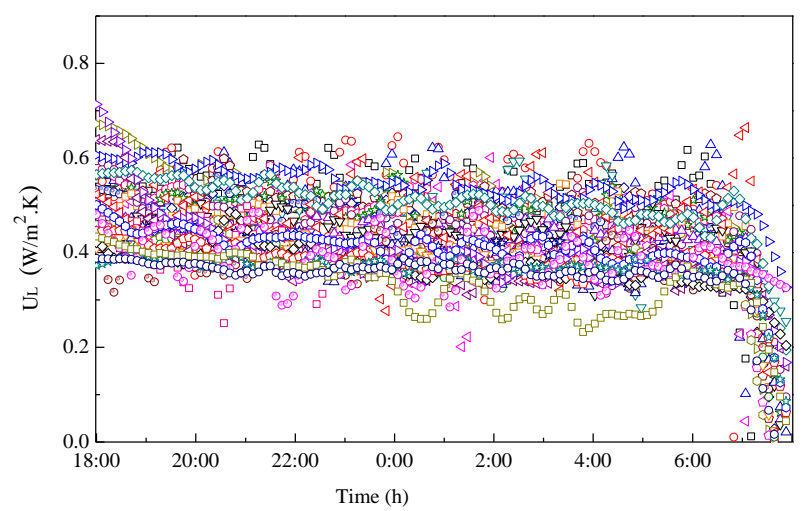

Fig. 5. The transient heat loss coefficient of the solar collector in winter night in quiescent conditions.

Fig. 5 exemplifies the 37 groups of transient heat loss coefficient in 22 nights. Generally speaking, the heat loss coefficient was around at $0.4 \mathrm{~W} / \mathrm{m}^{2} \cdot \mathrm{K}$ to $0.6 \mathrm{~W} / \mathrm{m}^{2} \cdot \mathrm{K}$ in most cases, and there was a slight decrease in each night. The transient heat loss coefficient fluctuates much larger at the beginning of the nights (18:00 PM), as well as the time after 7:00 AM. Because the fluid temperature was much higher at about 18:00 and the heat dissipation was large, the heat loss coefficient was correspondingly higher in some cases. After 7:00 AM, the heat loss coefficient decreased obviously from less than $0.4 \mathrm{~W} / \mathrm{m}^{2} \cdot \mathrm{K}$ to 0 in less than an hour. Indeed, it does not mean that the heat loss coefficient was dropped rapidly after 7:00 AM, but the sunrise and energy gains of solar collector. On the one hand, the results of the heat loss coefficient indicated that the solar collector has better insulation property, which was advantageous for the anti-freezing of collectors and outdoor pipes in severe cold areas. On the other hand, the heat loss coefficient was stabile and had no obvious change in the night, the nightly average value or a certain value range can be used to estimate the heat dissipation and possible lowest fluid temperature in similar weather conditions in consequence. The probability distribution of the minutely values of heat loss coefficient was presented in Fig. 6, which was more visual and can be perceived directly through the chart.

The heat loss coefficient are diverse in different nights because of the deviation of initial fluid temperature and the structural characteristics as mentioned above. Environmental parameters are also important factors that influence the heat loss coefficient, including the ambient air temperature, wind velocity, and the sky temperature, cloudage and atmospheric transparency, and so on. However, the correlations between the heat loss coefficient and the environment parameters is not linear, but a comprehensive function of weather parameters and the initial fluid temperature.

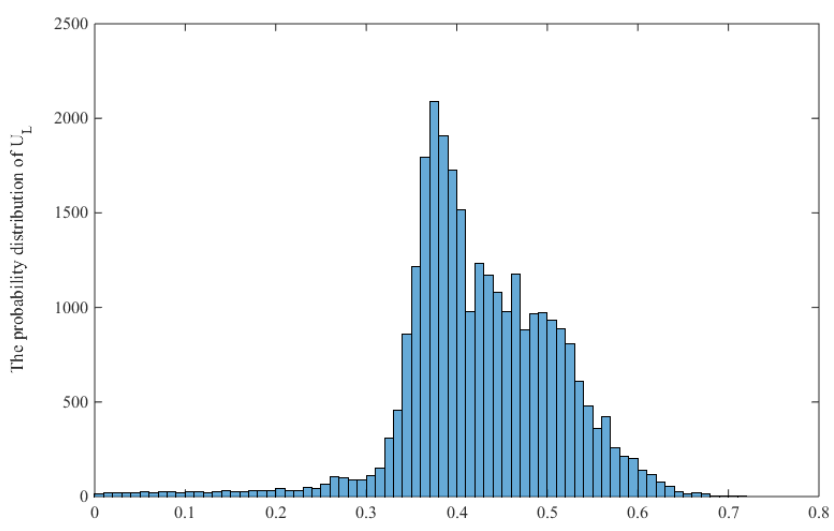

Fig. 6. The probability distribution of the minutely heat loss coefficient

\section{CONCLUSIONS}

The heat transfer of evacuated tube collector in actual conditions was a complicated process. Based on the heat balance equation, the heat loss coefficient of collector, as well as the possible fluid temperature in it, was analyzed and tested in winter nights. During the test, there are 37 groups of data in 22 nights. The initial fluid temperature was usually higher than $20^{\circ} \mathrm{C}$ in most of the days. Higher initial fluid temperature demonstrated that it was beneficial for the freezing protection in winter nights. After thermal dissipation in night, the lowest value of the fluid temperature was ranging from $5^{\circ} \mathrm{C}$ to $20^{\circ} \mathrm{C}$, which was varying with the initial fluid temperature and the outdoor weather conditions. The heat loss coefficient was around at $0.4 \mathrm{~W} / \mathrm{m}^{2} \cdot \mathrm{K}$ to $0.6 \mathrm{~W} / \mathrm{m}^{2} \cdot \mathrm{K}$ in most cases. The diversity of the heat loss coefficient was owing to the difference of initial fluid temperature and the structural characteristics of solar collector, as well as the environment parameters.

\section{ACKNOWLEDGMENT}

The authors acknowledge the financial support from the National Key Technology R\&D Program in the 12th Five Year Plan of China (No. 2013BAJ12B03).

\section{REFERENCES}

[1] Z. Li, C. Chen, H. Luo, Y. Zhang, and Y. Xue, "All-glass vacuum tube collector heat transfer model used in forced-circulation solar water heating system," Solar Energy, vol. 84, pp. 1413-1421, 2010.

[2] A. W. Badar, R. Buchholz, and F. Ziegler, "Experimental and theoretical evaluation of the overall heat loss coefficient of vacuum tubes of a solar collector," Solar Energy, vol. 85, pp. 1447-1456, 2011.

[3] R. Tang, Z. Li, H. Zhong, and Q. Lan, "Assessment of uncertainty in mean heat loss coefficient of all glass evacuated solar collector tube testing," Energy Conversion and Management, vol. 47, pp. 60-67, 2006.

[4] T. Olofsson and S. Andersson, "Overall heat loss coefficient and domestic energy gain factor for single-family buildings," Building \& Environment, vol. 37, pp. 1019-1026, 2002.

[5] T. Olofsson and S. Andersson, "Analysis of the interaction between heating and domestic load in occupied single-family buildings," in Proc. the Fifth Symposium on Building Physics in the Nordic Countries, 1999, vol. 2, pp. 473-480.

[6] L. Xu, Z. Wang, G. Yuan, X. Li, and Y. Ruan, "A new dynamic test method for thermal performance of all-glass evacuated solar air collectors," Solar Energy, vol. 86, pp. 1222-1231, 2012. 
[7] H. Liu, S. Zhang, Y. Jiang, and Y. Yao, "Feasibility study on a novel freeze protection strategy for solar heating systems in severely cold areas," Solar Energy, vol. 112, pp. 144-153, 2015.

[8] L. Ma, Z. Lu, J. Zhang, and R. Liang, "Thermal performance analysis of the glass evacuated tube solar collector with U-tube," Building \& Environment, vol. 45, pp. 1959-1967, 2010.

[9] Q. Tian, "Thermal performance of the U-type evacuated glass tubular solar collector," Building Energy and Environment, vol. 26, pp. 51-54, 2007.

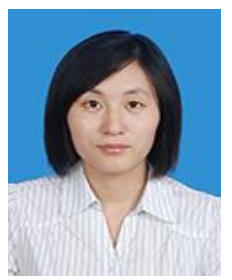

Huifang Liu is a PhD candidate, study at the School of Municipal and Environmental Engineering, Harbin Institute of Technology, Harbin, China. Her research interests include thermal utility of solar energy, anti-freezing of solar water systems in severe cold areas, and the thermal comfort and indoor air quality.

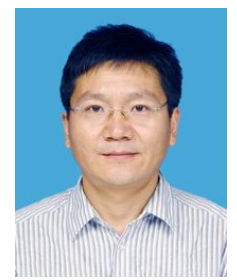

Yiqiang Jiang is a professor at the School of Municipal and Environmental Engineering, Harbin Institute of Technology (HIT). He is also the director of the Department of Building Thermal Energy Engineering of HIT. His research interests include renewable energy utilization, high-efficiency heat pump technology and application, multiphase flow, and heat transfer, etc.

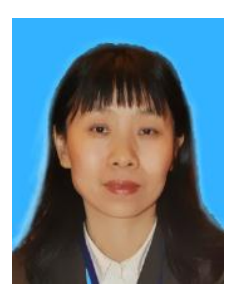

Yang Yao is a professor at the School of Municipal and Environmental Engineering, Harbin Institute of Technology, Harbin, China. Her research interests include high-efficiency heat pump technology and application, building energy efficiency, heating ventilation, air conditioning system simulation and control. 